\title{
COMMENTARY
}

\section{Increased blood flow by insulin infusion targeting normoglycemia in patients with severe sepsis: friend or foe?}

\author{
Greet Van den Berghe* \\ See related research by Žuran et al., http://ccforum.com/content/13/6/R198
}

\begin{abstract}
A small study in patients with severe sepsis suggested that insulin infused to normalize blood glucose levels increased forearm flow. This clinical observation supports the effect of insulin on the endothelium, as previously shown by in vitro studies and by in vivo animal models of critical illness, but the clinical consequences remain unclear.
\end{abstract}

In the previous issue of Critical Care, Dr Žuran and collaborators reported the results of an interesting, smallsized, open-label study investigating the effects of targeting different levels of blood glucose with insulin in patients with severe sepsis [1]. As compared with a blood glucose target of 7 to $11 \mathrm{mmol} / \mathrm{l}$, targeting a blood glucose level of 4.4 to $6.1 \mathrm{mmol} / \mathrm{l}$ increased forearm blood flow measured by the strain-gauge plethysmography method, at 24 and 72 hours after initiation of the intervention. These differences occurred in the absence of detectable differences in hemodynamics or patient outcome. The authors concluded that these data corroborate a protective effect on the endothelium, and attribute this to the amount of insulin rather than to the level of blood glucose control.

Žuran and colleagues' study is an interesting clinical observation made in a difficult setting of clinical practice treating patients with sepsis and organ failure, for which the authors ought to be congratulated. The small sample size, with a trend for slightly different baseline characteristics, particularly concerning the severity of the shock, as well as the nonblinded nature of the study,

${ }^{*}$ Correspondence: greet.vandenberghe@med.kuleuven.be Department of Intensive Care Medicine, Catholic University of Leuven, B-3000 Leuven, Belgium however, may have played a confounding role. Nevertheless, if the increase in forearm flow is indeed evoked by the more intensive insulin therapy, it corroborates extensive data from basic research in in vitro cellular models [2-4] and from in vivo animal research $[5,6]$, as well as observations in healthy subjects $[7,8]$ and on tissue samples obtained from patients in the proof-of-concept study on blood glucose control performed in Leuven $[9,10]$. Together, these previous data suggested that insulin signaling mediates a direct and/or indirect protection of the endothelium and the cardiovascular system, but that this is antagonized by concomitant pronounced hyperglycemia.

The antagonistic effect between insulin signaling and hyperglycemia on inflammation and blood flow is an interesting one, which is important to take into account when analyzing results of studies on the topic. In this light, the weak correlation in the current study by Žuran and colleagues between the forearm flow and the insulin doses, largely explained by one outlier, does not suffice to conclude that the concomitant prevention of hyperglycemia was not important, as both higher insulin doses and lower blood glucose levels were brought about simultaneously. Furthermore, it may be that a certain threshold of hyperglycemia needs to be avoided in order for insulin to exert a protective effect on the endothelium. In Žuran and colleagues' study, the large spread of the achieved blood glucose levels at all studied time points, and the very important overlap between the two study arms, does not allow one to define such a threshold. Indeed, the studied intervention was a complex one; an insulin regimen targeting lower blood glucose levels, and thus a weak correlation with the forearm flow of one aspect of this complex intervention (insulin dose) and the absence of a correlation with the other aspect of this complex intervention (blood glucose level achieved) the latter quite difficult to quantify accurately over time does not allow one to discard the importance of one aspect over the other. 
The clinical relevance of a reduction in forearm flow in patients with severe sepsis with intensified insulin therapy remains unclear, as recognized adequately by the authors. Firstly, one could question the relevance of the small observed effect size on forearm flow and the apparently transient nature. Indeed, the patients in the two groups remained hemodynamically comparable throughout the study and did not require different amounts of fluids, vasopressors or inotropes; and neither did they reveal any difference in organ function. Secondly, it remains obscure whether a change in forearm flow is giving any information on the vital organ perfusion and oxygenation. Indeed, an increase in blood flow to the skeletal muscle may either reflect an overall increase of flow to the body or instead may hint towards a steel phenomenon, hiding a decrease of flow to the vital organs. The clinical implications of these two possible interpretations are entirely different, as they may range from a beneficial protection of an important organ system to a deleterious silent risk for instability.

Despite these additional questions raised by the study presented by Žuran and colleagues, the elegant demonstration of the difference in forearm flow does indicate that the vasculature may indeed be affected by intensified insulin therapy. The observation nicely corroborates previous basic science data, and therefore requires further detailed investigation. Understanding the underlying mechanisms and the clinical consequences will provide further insight into the controversy that currently surrounds the concept of glucose control in ICU patients [11].

Acknowledgements

GVdB, via the Catholic University of Leuven, receives structural research financing from the Methusalem program, funded by the Flemish Government.

Competing interests

The author declares that he has no competing interests.

Published: 16 February 2010
References

1. Žuran I, Poredoš P, Skale R, Voga G, Gabršček L, Parežnik R: Intensive insulin treatment improves forearm blood flow in critically ill patients: a randomized parallel design clinical trial. Crit Care 2009, 13:R198.

2. Dandona P, Aljada A, Mohanty P, Ghanim H, Bandyopadhyay A, Chaudhuri A: Insulin suppresses plasma concentration of vascular endothelial growth factor and matrix metalloproteinase-9. Diabetes Care 2003, 26:3310-3314.

3. Dandona P, Aljada A, Chaudhuri A, Mohanty P: Endothelial dysfunction, inflammation and diabetes. Rev Endocr Metab Disord 2004, 5:189-197.

4. Dandona P, Aljada A, Chaudhuri A, Bandyopadhyay A: The potential influence of inflammation and insulin resitance on the pathogenesis and treatment of atherosclorosis-related complications in type 2 diabetes. J Clin Endocrinol Metab 2003, 88:2422-2429.

5. Ellger B, Debaveye Y, Vanhorebeek I, Langouche L, Giulietti A, Van Etten E, Herijgers $P$, Mathieu C, Van den Berghe G: Survival benefits of intensive insulin therapy in critical illness: impact of maintaining normoglycemia versus glycemia-independent actions of insulin. Diabetes 2006, 55:1096-1105.

6. Su H, Sun X, Ma H, Zhang H-F, Yu Q-J, Huang C, Wang X-M, Luan R-H, Jia G-L, Wang $\mathrm{H}-\mathrm{G}, \mathrm{Gao}$ F: Acute hyperglycemia exacerbates myocardial ischemia/ reperfusion injury and blunts cardioprotective effect of GIK. Am J Physiol Endocrinol Metab 2007, 293:E629-E635.

7. Stegenga ME, van der Crabben SN, Blümer RM, Levi M, Meijers JC, Serlie MJ, Tanck MW, Sauerwein HP, van der Poll T: Hyperglycemia enhances coagulation and reduces neurophil degranulation, whereas hyeprinsulinemia inhibits fibrinlysis during human endotoxinemia. Blood 2008, 112:82-89.

8. Blümer RM, van der Crabben SN, Stegenga ME, Tanck MW, Ackermans MT, Endert E, van der Poll T, Sauerwein HP: Hyperglycemia prevents the suppressive effect of hyperinsulinemia on plasma adiponectin levels in healthy humans. Am J Physiol Endocrinol Metab 2008, 295:E613-E617.

9. Van den Berghe G, Wouters PJ, Weekers F, Verwaest C, Bruyninckx F, Schetz M, Vlasselaers D, Ferdinande P, Lauwers P, Bouillon R: Intensive insulin therapy in critically ill patients. N Engl J Med 2001, 345:1359-1367.

10. Langouche L, Vanhorebeek I, Vlasselaers D, Vander Perre S, Wouters PJ, Skogstrand K, Hansen TK, Van den Berghe G: Intensive insulin therapy protects the endothelium of critically ill patients. J Clin Invest 2005, 115:2277-2286.

11. Van den Berghe G, Schetz M, Vlasselaers D, Hermans G, Wilmer A, Bouillon R, Mesotten D. Clinical review: Intensive insulin therapy in critically ill patients: NICE-SUGAR or Leuven blood glucose target? J Clin Endocrinol Metab 2009, 94:3163-3170.

doi:10.1186/cc8228

Cite this article as: Van den Berghe G: Increased blood flow by insulin infusion targeting normoglycemia in patients with severe sepsis: friend or foe? Critical Care 2010, 14:122. 